T. E. Letsoalo, J. E. Lowther (Johannesburg, South Africa)

\title{
Elastic and thermodynamic properties of potentially superhard carbon boride materials
}

Boron icosahedral structures are the basic building structures of many important hard borides and especially $B_{4} C$. The structural and thermodynamic properties of $B_{4} C$ have been examined applying molecular dynamics simulation with the use of both ab initio and bond order Tersoff potentials. Various physical quantities of $B_{4} C$ including the elastic constants, thermal expansion coefficients, and specific heat have been examined. molecular dynamics.

Keywords: diamond, boron, electronic structure, elastic constants,

\section{INTRODUCTION}

Lightweight atoms such as carbon, boron, nitrogen, and oxygen [1] are very important for hard materials. Carbides, borides, nitrides, and oxides have high melting points, good thermal conductivity, and high chemical resistance [2-5]. Cubic boron nitride is an important hard material, which behaves as an electrical insulator and has several properties similar to diamond. Recent work has focused on alloying diamond with BN to identify superhard materials with a B-C$\mathrm{N}$ structure [6-8]. The hope is that a high pressure solid solution of diamond and $\mathrm{BN}$ would exhibit novel properties and be a superhard material. B-C-N phases are expected to be harder than $\mathrm{cBN}$, but still retain good thermal and chemical stability. This therefore would be an excellent material for high-speed cutting and polishing of ferrous alloys where diamond fails.

Another interesting class of lightweight materials are boron-rich solids. Boron has several crystallographic allotropes, many of which are classified as semiconductors and capable of forming stable covalent-bonded molecular networks with high strength $[9,10]$. The crystal structures mainly contain $B_{12}$ icosahedra as essential common structural building blocks [11-13] and these solids have similar physical properties such as high electrical conductivity, high melting points, low density, high chemical resistance. They also have low corrosivity and high hardness. The boron icosahedra primarily determine the electronic structure and chemical bonding in these solids and this is the reason, why such materials display similar characteristics. They also have advantages of being easily synthesized and stable up to very high temperatures [14]. Recent theoretical works [12, 15] have concluded that the incorporation of other atoms between the icosahedra indirectly influences the bonding between the boron atoms and is responsible for the enhanced hardness.

There are several allotropes of boron, although three of them, $\alpha, \beta$, and tetragonal, are important. The allotrope $\beta$-boron is synthesized at a high temperature, while $\alpha$-boron is metastable at ambient conditions, unstable thermodynamically, and synthesized only at low temperatures. Tetragonal phases are intermediate 
between $\alpha$ and $\beta$-boron. The boundary temperature depends on the preparation method and has been estimated to be about $1500 \mathrm{~K}[16,17]$. In the case of the $\mathrm{B}_{50}$ allotropes, a $\mathrm{B}_{192}$ structure may be more appropriate [18]. Boron carbides are among the best studied $[18,19]$ for potential as a hard material. $\mathrm{B}_{4} \mathrm{C}$ has often been considered to have a stucture similar to $\alpha$-boron [18]. Technical applications of such boron-carbon structures are limited with variable homogeneity range over a specific stoichiometry around $\mathrm{B}_{4} \mathrm{C}$. However, detailed investigation of fundamental properties of such boron compounds has been impeded because it is difficult to grow large crystals. There have been several speculations concerning the structure of $\mathrm{B}_{4} \mathrm{C}$. However, recently it has been shown that the polar structure (where $\mathrm{C}$ enters the icosahedra) is more likely associated with a $\mathrm{B}_{13} \mathrm{C}_{2}$ stoichiometry [20] than the conventional chain structure (where $\mathrm{C}$ does not enter the icosahedra) with $\mathrm{B}_{4} \mathrm{C}$ [21-23].

Computer modeling techniques have also been used to study boron and boronrich compounds. $\mathrm{Li}$ and Ching [24] studied the structure and properties of four $\mathrm{B}_{12^{-}}$ based crystals using the self-consistent orthogonalized linear combination with the local density approximation (LDA) of the density functional theory (DFT) to calculate the band structures and ground state properties. Their results were in good agreement with other existing first-principle calculations using the pseudopotential plane-wave method. Various attempts have been made to study the ground state and finite temperature properties of $\alpha$ - and $\beta$-boron using ab initio pseudopotentials method with LDA $[15,16]$. These have clarified the features of $\beta$-boron by comparing them to those of the $\alpha$-boron phase. Electronic structures of various other borides that hold potential for superhard material properties have also been investigated [12]. Recently [23] the mechanical properties and structure of amorphous and crystalline $\mathrm{B}_{4} \mathrm{C}$ prepared using various plasma-based techniques have been investigated and it has been suggested that carbon could eventually segregate into clusters when the material attains an amorphous structure at elevated temperatures.

In the present work we investigated structural and thermodynamic properties of selected boron icosahedra materials and $\mathrm{B}_{4} \mathrm{C}$ using both the ab initio and molecular dynamic simulations. The molecular dynamic simulations are employed as being a way to investigate the behavior of large numbers of atoms and thus the material behavior at high temperatures. The results are presented for the lattice expansion and specific heat of $\mathrm{B}_{4} \mathrm{C}$. Finally it is shown that the behavior of carbon appears to play an important role at high temperatures.

\section{CALCULATIONS}

The computer simulation gives information at a microscopic atomic level [24, 25], from which experimental properties are derived or predicted. Ab initio approaches can accurately predict many physical properties but have computational limitations as to practical realization to deal with a relatively low number of atoms. In the present work, first-principles calculations have used the VASP code [26], which performs plane-wave pseudopotential total energy calculations. The electronic structure of the materials have been invetigated using several methods [27, $28]$ and here they are calculated using the density functional theory (DFT) in the local density approximation (LDA) with the Ceperley and Alder [29] correlation used to treat the exchange and correlation functional. In all calculations, plane waves are employed with an energy cut-off to $500 \mathrm{eV}$, and the Brillouin zone sampling is fixed at $8 \times 8 \times 8$ Monkhorst-Pack [30] scheme with PAW pseudopotentials 
[31]. All the calculations carried out are fully relaxed and optimized with respect to volume with an energy convergence criteria of $10^{-5} \mathrm{eV} /$ atom.

For large numbers of atom simulations we have used the Tersoff bond-order potential as implemented either through the codes DLPLOLY [32] or GULP [33]. This potential has now been applied to a large variety of different systems [34-36] and is one of the commonly used functional forms for modeling covalent systems. The functional form of the Tersoff potential is:

$$
\begin{aligned}
& V=\sum_{i} v_{i}=\frac{1}{2} \sum_{i \neq j} v_{i j} ; \\
& v_{i j}=f_{C}\left(r_{i j}\right)\left[f_{R}\left(r_{i j}\right) b_{i j} f_{A}\left(r_{i j}\right)\right],
\end{aligned}
$$

where $V$ is the total potential energy of the system, $f_{R}$ and $f_{A}$ are the repulsive and attractive pair potentials, respectively, and $f_{C}$ is a cutoff function. These are given by

$$
\begin{gathered}
f_{R}\left(r_{i j}\right)=A_{i j}\left(r_{i j}\right) e^{-\lambda_{i j} r_{i j}} ; \\
f_{A}\left(r_{i j}\right)=-B_{i j}\left(r_{i j}\right) e^{-\lambda_{i j} r_{i j}} ; \\
f_{C}\left(r_{i j}\right)= \begin{cases}1 & \text { at } r_{i j}<R-D ; \\
\frac{1}{2}-\frac{1}{2} \sin \left[\frac{\pi}{2} \frac{\left(r_{i j}-R\right)}{D}\right] & \text { at } R-D<r_{i j}<R+D ; \\
0 & \text { at } r>R+D ;\end{cases}
\end{gathered}
$$

where $r_{i j}$ is the bond distance between atoms $i$ and $j$ with $D$ and $R$ cutoff radii for the interaction potential. The $A, B$ and $\lambda_{i j}$ potential parameters and the strength of each bond depend upon the local environment as measured by another empirical parameter $\chi_{i j}$. In the case of the boron only system the cut off parameter $D$ was adjusted to simulate icosahedral boron potentials, whereas for $\mathrm{B}_{4} \mathrm{C}$ the parameter $\chi_{B-C}$ was adjusted. The parameters we have used in this work are listed in Table 1.

Table 1. Tersoff potential parameters used in this study. Parameters for $B$ and $C$ are taken from Matsunaga [37] and Munetoh [38]. Some parameters were adjusted as discussed in the text

\begin{tabular}{ccc}
\hline & $\mathrm{B}$ & $\mathrm{C}$ \\
\hline$A, \mathrm{eV}$ & $2.7702 \cdot 10^{2}$ & $1.3936 \cdot 10^{3}$ \\
$B, \mathrm{eV}$ & $1.8349 \cdot 10^{2}$ & $3.467 \cdot 10^{2}$ \\
$\lambda, \AA^{-1}$ & 1.992 & 3.4879 \\
$\mu, \AA^{-1}$ & 1.5856 & 2.2119 \\
$\mathrm{~B}$ & $1.6000 \cdot 10^{-6}$ & $1.5724 \cdot 10^{-7}$ \\
$N$ & 3.9929 & 0.72751 \\
$C$ & $5.2629 \cdot 10^{-1}$ & $3.8049 \cdot 10^{4}$ \\
$D$ & $1.5870 \cdot 10^{-3}$ & 4.384 \\
$H$ & 0.500 & -0.57058 \\
$R, \AA$ & 1.8 & 1.8 \\
$D, \AA$ & $1.7-2.1$ & 2.1 \\
Interactions $(i-j)$ & $\mathrm{B}-\mathrm{C}$ & \\
$\chi_{i j}$ & 1.0025 & \\
$\omega_{i j}$ & 0.9810 & \\
\hline
\end{tabular}




\section{Structural properties}

Initially we examined the structural properties of some boride phases as well as $\mathrm{B}_{4} \mathrm{C}$. The boron structures studied are $\alpha$-boron, tetragonal boron and crystal structures of these together with the $\mathrm{B}_{4} \mathrm{C}$ phase we have considered are shown in Fig. 1. The reason for choosing these borides is to attempt some indication of the reliability of the Tersoff potential, although we stress that our prime motivation here is to explore properties of $\mathrm{B}_{4} \mathrm{C}$. Details of the final geometries are given in Table 2.
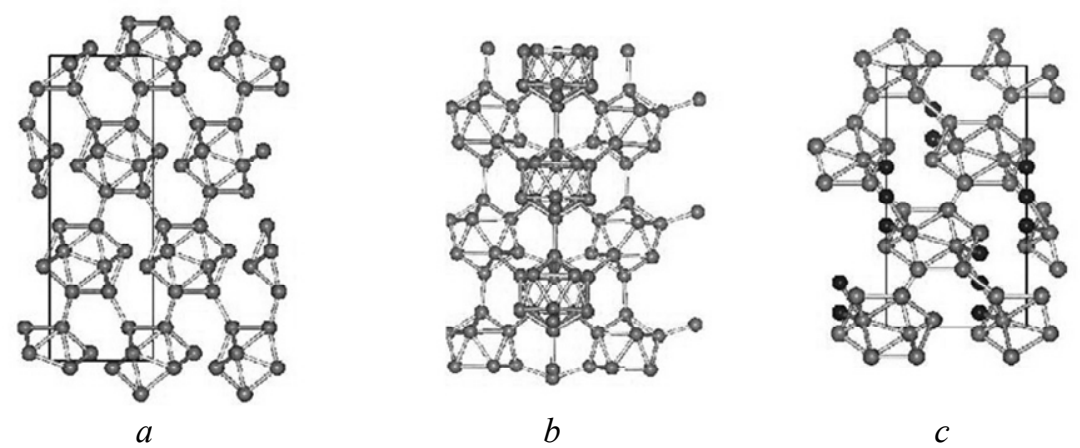

Fig. 1. Various boride phases (a) $\alpha$-boron, (b) tetragonal boron, $(c) \mathrm{B}_{4} \mathrm{C}$.

Table 2. Lattice parameter $(\AA)$ and bulk moduli of some boron-related compounds. Bulk moduli are obtained from the Birch-Murnaghan equation of state

\begin{tabular}{c|c|c|c|c|c|c}
\hline Material & Tersoff & Ab initio & Experiment & $\begin{array}{c}B,\left(B^{\prime}\right) \\
(\text { Tersoff })\end{array}$ & $\begin{array}{c}B,\left(B^{\prime}\right) \\
(a b \text { initio })\end{array}$ & Experiment \\
\hline$\alpha-\mathrm{B}_{12}(R 3 m)$ & $a=4.404$ & $a=4.844$ & $a=5.507[39]$ & $212,(2.26)$ & $226,(3.80)$ & $213-224[36]$ \\
& $c=12.286$ & $c=12.286$ & & & $(4.0)$ \\
$\mathrm{T}-\mathrm{B}_{50}$ & $a=7.940$ & $a=8.734$ & $a=8.75[40,41]$ & $208,(1.84)$ & $206,(3.80)$ & \\
$\left(P 4_{2} / n n m\right)$ & $c=4.718$ & $c=5.010$ & $c=5.06[42]$ & & & \\
$\mathrm{B}_{4} \mathrm{C}(R 3 m)$ & $a=5.174$ & $a=5.577$ & $a=5.61$ & $246,(5.380)$ & $229,(3.50)$ & $199-241[37]$ \\
& $c=11.695$ & $c=11.286$ & $c=12.14$ & & $(1.0,4.0)$ \\
\hline
\end{tabular}

We have then applied a uniform pressure to each of the phases and fitted the energy results to the Birch-Murnaghan equation of state using the molecular dynamics code DLPOLY. The pressure-volume relation is shown in Fig. 2 for borides and the $\mathrm{B}_{4} \mathrm{C}$ structure.

It is clear that the compressibility of $\mathrm{B}_{4} \mathrm{C}$ is better than of the boron structures and this is reflected in the value of the bulk moduli obtained from a least squares fit to the Birch-Murnaghan equation of state that is given in Table 2. However the bulk modulus derived in this way does not reflect the full elastic properties of the system. To this end we specifically investigated the full elastic constants of the $\mathrm{B}_{4} \mathrm{C}$ material and such values are given in Table 3 as obtained from the GULP program molecular dynamics code. We have also included results of the elastic constants obtained using ab intio calculations through the VASP code. As seen from Table 3 overall there is quite good agreement between the Tersoff and $a b$ initio results, and with previous calculations, and experiment where available. This 
gives some confidence in applying the Tersoff potential to finite temperature simulations, where large numbers of atoms are really needed and the system may become disordered.

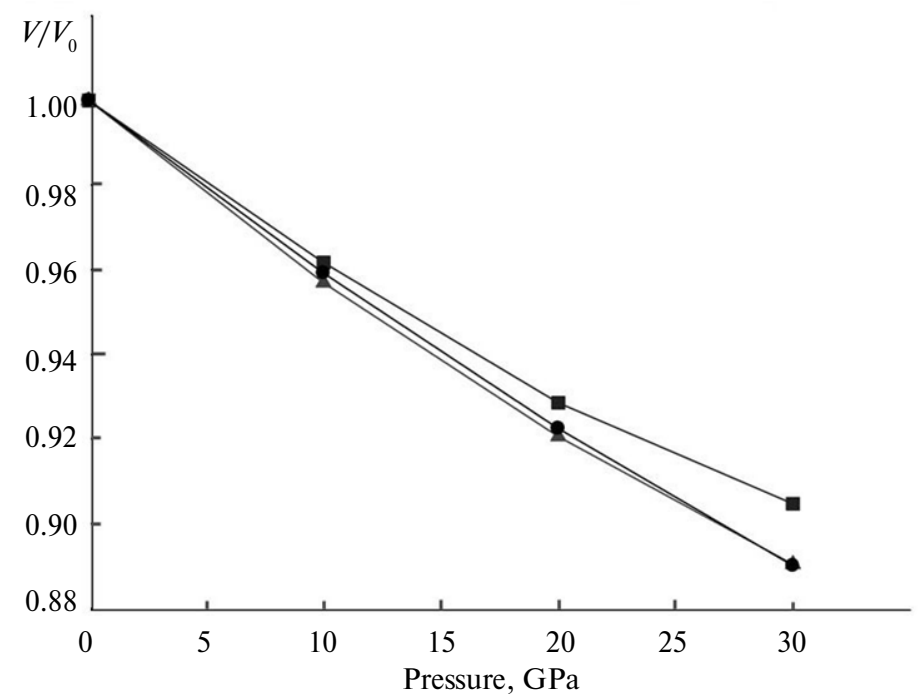

Fig. 2. Pressure-volume relations of $\alpha$-boron $\left(B_{12}\right)(\bullet)$, tetragonal-boron $\left(B_{50}\right)(\boldsymbol{\Delta})$ and $B_{4} C$ (polar) (घ).

Table 3. Calculated elastic properties of $B_{4} C(G P a)$. Other calculation and experimental values are listed. Voigt bulk $(B)$, shear $(G)$ and Young $(E)$ moduli obtained from the elastic moduli tensors

\begin{tabular}{c|c|c|c|c|c|c|c|c|c}
\hline & $c_{11}$ & $c_{12}$ & $c_{13}$ & $C_{23}$ & $C_{33}$ & $C_{55}$ & $B$ & $G$ & $E$ \\
\hline Present (Tersoff) & 540 & 180 & 91 & 32 & 520 & 305 & 234 & 200 & 467 \\
Present (ab initio) & 539 & 181 & 79 & 82 & 480 & 139 & 236 & 178 & 427 \\
Other calc. [44] & 562 & 123 & 69 & 17 & 517 & - & 234 & - & - \\
Expt. [45] & 543 & 132 & 63 & & 534 & 164 & 241 & 193 & 457 \\
Expt. [46] & & & & & & & 235 & 197 & 462 \\
\hline
\end{tabular}

\section{Thermal properties of $\mathrm{B}_{4} \mathrm{C}$}

An increase in the temperature increases the kinetic energy of atoms and the increased interaction between the atoms gives and effective expansion of the unit lattice cell. The possibility of disorder in the structures at very high temperatures cannot be ruled out. To investigate, this needs quite a large number of atoms. For this we have used supercells consisting of up to 2880 atoms. All simulations have been preformed using a NVT ensemble with the DLPOLY code, and employing a Verlet algorithm, with a time step of 1 ps.

First in Fig. 3 are the plots of the lattice expansion of $\mathrm{B}_{4} \mathrm{C}$ at zero pressure. We note small changes in the lattice occurring around $T=1500 \mathrm{~K}$. For this reason we have fitted the calculated results to a polynomial and this is shown in the figures. Thermal expansion coefficients $\alpha_{a}$ and $\alpha_{c}$ along $a$ and $c$ axes in MD simulation can be computed directly from the temperature derivative of the lattice parameter along those axes 


$$
\alpha_{(a, c)}=\frac{1}{(a, c)} \frac{\partial(a, c)}{\partial T}
$$

where $a$ and $c$ are the lattice parameters along the $a$ or $c$ axes. The thermal expansion coefficient increases linearly with temperature and we obtained a slightly larger thermal expansion along the $c$ axis than along the $a$ axis at $300 \mathrm{~K}$.

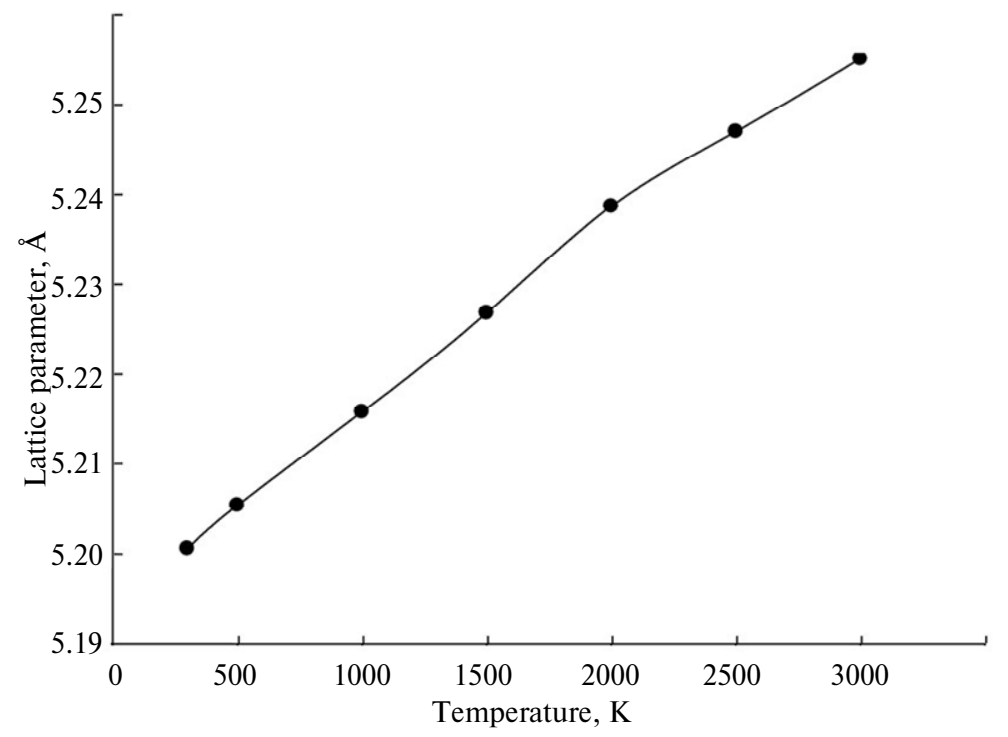

$a$

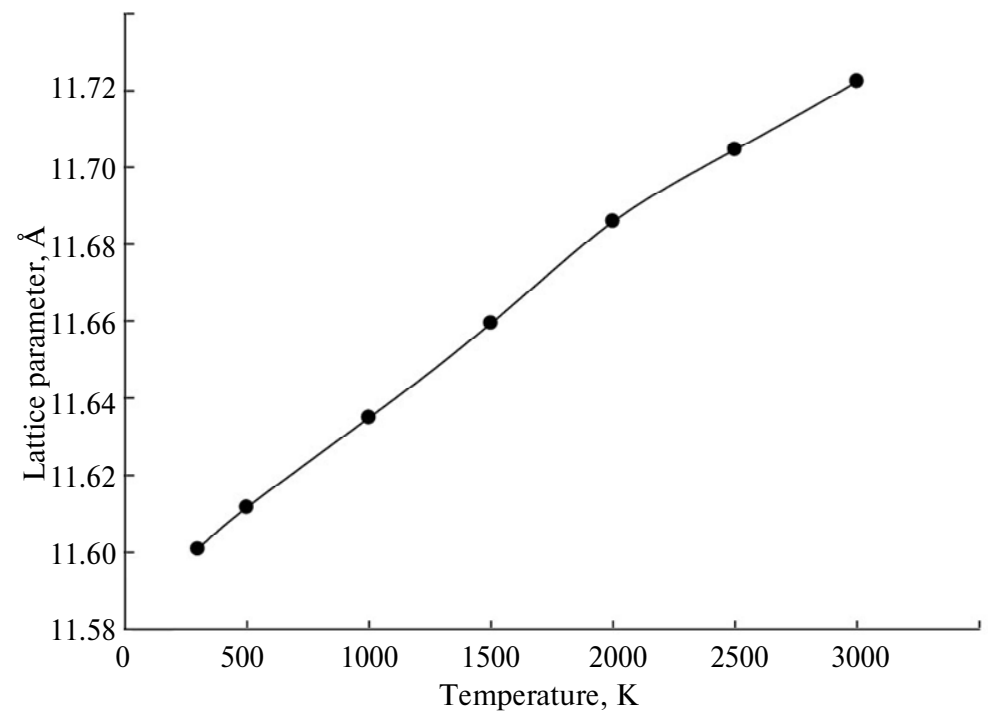

$b$

Fig. 3. Temperature dependence of the $a$ - and $c$-axes of $\mathrm{B}_{4} \mathrm{C}:(a) a_{300 \mathrm{~K}}(T)=-1.437 \cdot 10^{-9} T^{2}+$ $2.517 \cdot 10^{-5} T+5.193, a_{1500 \mathrm{~K}}(T)=-3.800 \cdot 10^{-9} T^{2}+3.574 \cdot 10^{-5} T+5.182 ; \quad(b) c_{300 \mathrm{~K}}(T)=$ $-3.374 \cdot 10^{-9} T^{2}+5.636 \cdot 10^{-5} T+11.58, c_{1500 \mathrm{~K}}(T)=-8.600 \cdot 10^{-9} T^{2}+8.022 \cdot 10^{-5} T+11.56$.

An average linear thermal expansion coefficient, $\alpha_{l}$, was calculated using the formula

$$
\alpha_{l}=\frac{1}{3}\left(2 \alpha_{a}+\alpha_{c}\right)
$$


The results for the average expansion coefficient of these borides starting at 300 and $1500 \mathrm{~K}$ computed using the above equation are listed in Table 4 . These results are compared with two strongest known hard materials diamond and boron nitride.

Although the melting of solids is one the most common observations of a phase transition, the mechanism of melting is still an outstanding problem in condensed matter physics [42]. On the basis of the thermodynamics theory a phase transition is characterized by an abrupt change in the slope of the total energy against the temperature curve. Figure 4 shows the variation of energy against the temperature for borides.

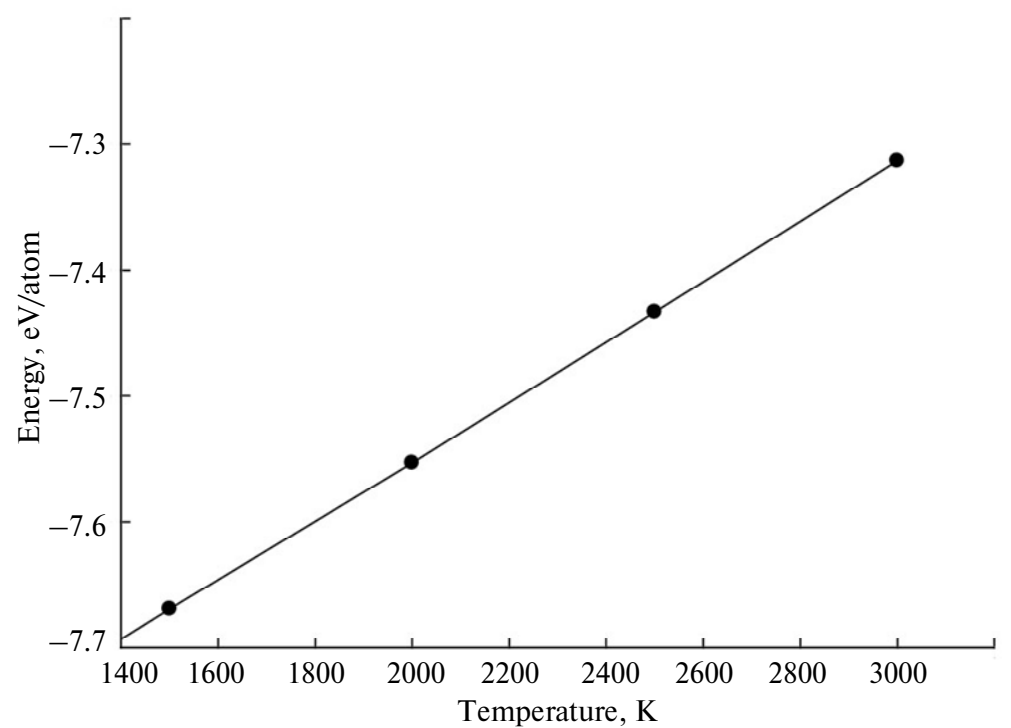

Fig. 4. Temperature variation of the total energy of $\mathrm{B}_{4} \mathrm{C}: E(T)=2.375 \cdot 10^{-4} T-8.027$.

There is a very slight change in the slope around $1500 \mathrm{~K}$. This suggests a possible change of a phase. But the energy/temperature behavior also allows some deduction of the specific heat of the materials. The values so deduced are given in Table 4 for $\mathrm{B}_{4} \mathrm{C}$. These values are also compared with two other hard materials, namely diamond and $\mathrm{cBN}$. As expected, the values compare quite well.

Table 4. Thermodynamic properties of $\mathrm{B}_{4} \mathrm{C}$ compared to other hard materials

\begin{tabular}{ccccc}
\hline & Diamond & BN & B C (calculated) \\
\hline$\alpha_{l_{300 K}}, 10^{-6} K^{-1}$ & $1.017^{b}$ & $1.8^{d}$ & 3.116 \\
$\alpha_{l_{1500 K}}, 10^{-6} K^{-1}$ & $5.181^{b}$ & $5.47^{c}$ & 4.598 \\
& & $6-8^{f}$ & 4.5 \\
$C_{v}\left(k_{\mathrm{B}}\right)$ & $2.97^{a}$ & $3.02^{c}$ & 2.76 \\
\hline
\end{tabular}

Note. The data taken from the following Refs. are indicated as: $[43]^{a},[44]^{b},[45]^{c},[46]^{d},[47]^{e}$, $[48]^{f}$.

We have to explore further the apparent change taking place around $1500 \mathrm{~K}$. To understand this we have examined the radial distribution function (RDF) of the $\mathrm{C}$ 
and $\mathrm{B}$ atoms as obtained from the MD calculations. Figure 5 shows the RDF for $\mathrm{B}_{4} \mathrm{C}$ at 300,1500 and $3000 \mathrm{~K}$. The results are quite striking in the case of C. Overall some peaks decreased, while others broadened at high temperatures, the broadening of the larger distance peaks is characteristic of some amorphization. The retention of the lower peaks related to B shows that the B icosahedra are still quite stable even at elevated temperature, but the pronounced change in the $\mathrm{C}$ peak suggest some mobility of $\mathrm{C}$ and even the formation of carbon related defects as suggested in [23].

\section{CONCLUSIONS}

In summary we have calculated the properties of boron icosahedral structures using molecular dynamics simulations. The Tersoff parameters used are found to be reasonably reliable to investigate structural and thermodynamic properties of the boron icosahedral structures studied here when compared with ab initio results and
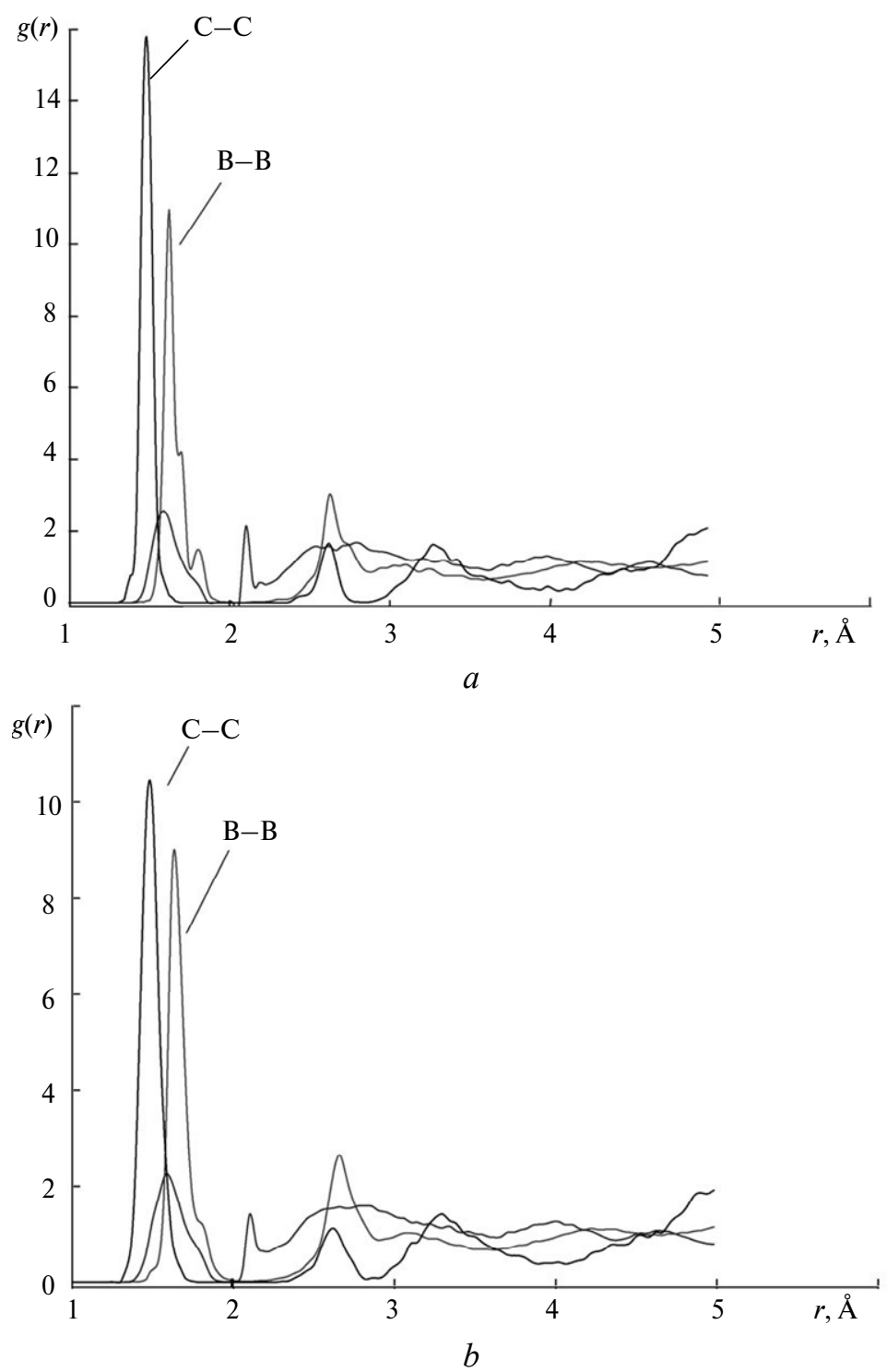

Fig. 5. Radial distribution of various atomic interactions in $\mathrm{B}_{4} \mathrm{C}: 300(a), 1500(b), 3000(c) \mathrm{K}$. 


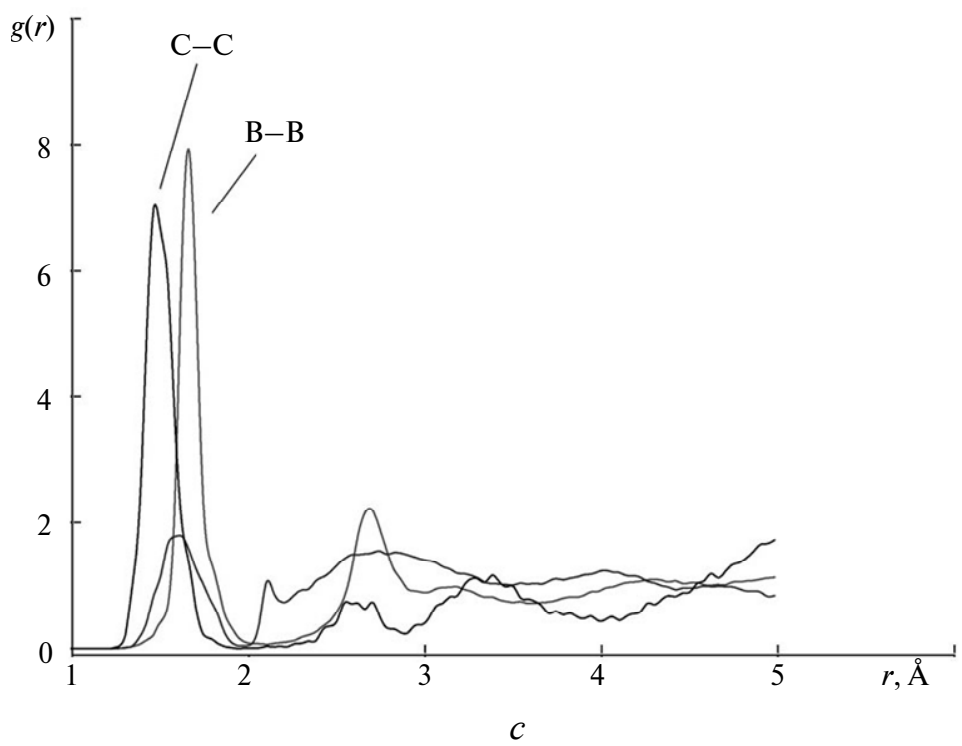

Fig. 5. (Contd.)

we suggest that with proper adjustment of the parameters they can be used to give insight into the complex structures. In the case of several thousands of atoms (as needed for very high temperature examination) possibly the Tersoff potential method is tentatively a way forward. Using the potential we also predicted thermodynamic properties such as linear thermal expansion coefficient and specific heat of the $\mathrm{B}_{4} \mathrm{C}$ structure and compared this with experiment. It has been suggested on the basis of the Tersoff results that the structure of B icosahedra seems to be quite stable even at high temperature, whereas $\mathrm{C}$ atoms are more mobile and this could lead to some clustering of the $\mathrm{C}$ atoms.

Ікосаедрічні структури бору є основними будівельними конструкціями багатьох важливих твердих боридів і особливо ие стосується $B_{4} C$. Досліджено структурні та термодинамічні властивості $B_{4} C$ при застосуванні моделювання динаміки молекул з використанням як ab initio розрахунків, так і потенціалів Терсоффа. Розглянуті різні фізичні характеристики $B_{4} C$, включаючи пружні константи, коефічієнти теплового розширення і теплоємність.

Ключові слова: алмаз, бор, електронна структура, пружні константи, молекулярна динаміка.

Икосаэдрические структуры бора являются основными строительными конструкииями многих важных твердых боридов и особенно это касается $B_{4} C$. Исследованы структурные и термодинамические свойства $B_{4} C$ с применением моделирования динамики молекул, используя как аb initio расчеты, так и потенциаль Терсоффа. Рассмотрены различные физические характеристики $B_{4} C$, включая постоянные упругости, коэффициенты теплового расширения и теплоемкость.

Ключевые слова: алмаз, бор, электронная структура, постоянные уnругости, динамика молекул.

1. Wu B. R., Sung C. M., Lee F. E., Tai M. F. A First principles study of physical properties of monoatomic structures of B, C, N, and O // Chinese J. Phys. - 2002. - 40. - P. 187-196.

2. Oganov A. R., Solozhenko V. L. Boron: a hunt for superhard polymorphs // J. Superhard Materials. -2009 . - 31, N 5. - P. 285-291.

3. McMillan P. F. New materials from high-pressure experiments // Nature Mater. - 2002. - 1. P. 19-25. 
4. Gregoryanz E., Sanloup C., Soyamazulu S. et al. Synthesis and characterization of a binary noble metal nitride // Ibid. - 2004. - 3. - P. 294-297.

5. Lowther J. E. Potential super-hard phases and the stability of diamond-like boron-carbon structures // J. Physics: Condensed Matter. - 2005. - 17. - P. 3221-3228.

6. Chen S., Gong X. G. Superhard pseudocubic $\mathrm{BC}_{2} \mathrm{~N}$ superlattices // Phys. Rev. Lett. - 2007. 98, art. 015502.

7. Kaner R. B., Gilman J. J., Tolbert S. H. Designing superhard materials // Science. - 2005. 308. - P. 1268-1273.

8. Mattesini M., Matar S. F. Search for ultra-hard materials: theoretical characterisation of novel orthorhombic $\mathrm{BC}_{2} \mathrm{~N}$ crystals // Int. J. Inorg. Mater. - 2001. - 3. - P. 943-947.

9. Emin D. Icosahendra boron rich solids // Phys. Today. - 1987. - 20. - P. 55-59.

10. Gao F. M., Hou L., He Y. H. Origin of superhardness in icosahedral Boron materials // J. Phys. Chem. B. - 2004. - 108, art. 13069.

11. Lowther J. E. Possible ultra-hard materials based upon boron icosahedra // Physica B. - 2002. - 322. - P. 173-178.

12. Letsoalo T. E., Lowther J. E. Computational Investigation into elastic properties of bulk and defective ultra hard $\mathrm{B}_{6} \mathrm{O} / /$ J. Superhard Materials. - 2011. - 33, N 1. - P. 19-25.

13. McColm I. J. Ceramic Hardness. - New York: Plenum Press, 1990. - 324 p.

14. Letsoalo T. E. and Lowther J. E. Systematic trends in boron icosahedral structured materials // Physica B. - 2008. - 403. - P. 2760-2765.

15. Suleyman E., de Wijs G. A, Brocks G. DFT study of planar boron sheets: a new template for hydrogen storage // J. Phys. Chem. - 2009. - 13, art. 18962.

16. Widom M., Mihalkovic M. Crystal relative stability of $\alpha$ and $\beta$ boron // J. Physics: Conf. Series. - 2009. - 176, art. 012024.

17. Vast N., Baroni S., Zerah G. et al. Lattice dynamics of icosahedral alpha-boron under pressure // Phys. Rev. Lett. - 1997. - 78. - P. 693-696.

18. Will G., Ploog K. Crystal structure of I-tetragonal boron // Nature. - 1974. - 251. - P. $406-$ 408.

19. Lee H., Speyer R. F. Hardness and fracture toughness of pressureless-sintered boron carbide $\left(\mathrm{B}_{4} \mathrm{C}\right) / /$ J. Am. Ceram. Soc. -2002 . - 85. - P. 1291-1293.

20. Gao F., Qin X., Wang L. et al. Prediction of new superhard boron-rich compounds // J. Phys. Chem. B. - 2005. - 109, art. 14892.

21. Feng Y., Seidler G. T, Cross C. et al. Role of inversion symmetry and multipole effects in nonresonant $\mathrm{x}$-ray Raman scattering from icosahedral $\mathrm{B}_{4} \mathrm{C} / /$ Phys. Rev. B. - 2004. - 69, art. 125402.

22. Oganov A. R., Solozhenko V. L. Boron: a hunt for superhard polymorphs // J. Superhard Materials. - 2009. - 31, N 5. - P. 285-291.

23. Oganov A. R., Chen J., Gatti C. et al. Ionic high-pressure form of elemental boron // Nature. - 2009. - 457. - P. 863-865.

24. Li D., Ching W. Y. Electronic structures and optical properties of low- and high-pressure phases of crystalline $\mathrm{B}_{2} \mathrm{O}_{3} / /$ Phys. Rev. B. - 1996. - 54. - P. 13616-13622.

25. Kulikovsky V., Vorlicek V., Bohac R. et al. Mechanical properties and structure of amorphous and crystalline $\mathrm{B}_{4} \mathrm{C}$ films // Diamond Relat. Mater. - 2008. - 18. - P. 27-33.

26. Allen M. P., Tildesley D. J. Computer Simulation in Chemical Physics. - New York: Kluwer Academic Publishers, 1993. - 521 p.

27. Heermann D. W. Computer Simulation Methods in Theoretical Physics. - Berlin: SpringerVerlag, 1990. $-148 \mathrm{p}$.

28. Kresse G., Hafner J. Ab initio molecular dynamics for liquid metals // Phys. Rev. B. - 1993. - 47. - P. 558-561.

29. Ceperley D., Alder B. Ground state of the electron gas by a stochastic method // Phys. Rev. Lett. -1980 . - 45. - P. 566-570.

30. Monkhorst H. J., Pack J. D. Special points for Brillouin-zone integrations // Phys. Rev. B. 1976. - 13. - P. 5188-5193.

31. Kresse G., Joubert D. P. From ultrasoft pseudopotentials to the projector augmented wave method // Ibid. - 1999. - 59. - P. 1758-1767.

32. Smith W., Forester T. Molecular dynamics of structured materials // J. Molecular Graphics. 1996. - 14. - P. 136-148.

33. Gale J. D. Gulp: A computer program for the symmetry-adapted simulation of solids // J. Chem. Soc., Faraday Trans. - 1997. - 1. - P. 629-641. 
34. Tersoff J. Empirical interatomic potential for silicon with improved elastic constants // Phys. Rev. B. - 1988. - 38. - P. 9902-9905.

35. Tersoff $J$. Modeling solid-state chemistry: interatomic potentials for multicomponent systems // Ibid. - 1989. - 39. - P. 5566-5568.

36. Chen E. T., Barnett R. N., Landman U. Surface melting of Ni(110)// Ibid. - 1990. - 41, N 1. - P. 439-450.

37. Matsunaga K., Fisher C., Matsubara $H$. Tersoff potential parameters for simulating cubic Boron Carbonitrides // Jpn. J. Appl. Phys. - 2000. - 39, Part 2, N 1A/B. - P. L48-L54.

38. Munetoh S., Motooka T., Moriguchi K., Shintani A. Interatomic potentials for $\mathrm{Si}-\mathrm{O}$ systems using Tersoff parametization // Computational Mater. Sci. - 2007. - 39. - P. 334-340.

39. Deker B. and Kasper B. Crystallographic Structure of various phases of boron // Acta Crystallograhy. - 1959. - 12. - P. 503-509.

40. Nieto-Sanz D., Loubeyre P., Crichton W., Mezouar M. X-ray study of the synthesis of boron oxides at high pressure: phase diagram and equation of state // Phys. Rev. B. - 2004. - 70, art. 214108.

41. Hoard J., Hughes R. E., Sands D. E. The structure of tetragonal boron // J. Am. Chem. Soc. 1958. - 80. - P. 4507-4510.

42. Delaye J. M. Modeling of multicomponent glasses: a review // Curr. Opin. Solid State Mat. Sci. - 2001. - 5, N 5. - P. 451-478.

43. Ivashchenko V. I., Shevchenko V. I., Turchi P. E. A. First-principles study of the atomic and electronic structures of crystalline and amorphous $\mathrm{B}_{4} \mathrm{C} / /$ Phys. Rev. B. - 2009. - 80, art. 235208.

44. Lee S. D., Bylander M., Kleinmann L. Elastic moduli of $\mathrm{B}_{12}$ and its compounds // Ibid. 1992. - 45. - P. 3245-3251.

45. McClellan K. J., Chu F., Roper J. M., Shingo I. Room temperature single crystal elastic constants of boron carbide // J. Mater. Sci. - 2001. - 36. - P. 3403-3409.

46. Manghnani M. H., Wang Y., Li F. et al. Elastic and vibrational properties of $\mathrm{B}_{4} \mathrm{C}$ to $21 \mathrm{GPa} / /$ Proc. 17th AIRAPT Conf.: Science and Technology of High Pressure. - Hyderabad, India: Universities Press, 2000. - P. 945-948.

47. Pierson H. O. Handbook of Carbon, Graphite, Diamond and Fullerenes: Properties, Processing and Applications. - London: Noyes Publications, 1993. - 417 p.

48. Reeber $R$. R., Wang $K$. Thermal expansion, molar volume and specific heat of diamond from 0 to $3000 \mathrm{~K} / /$ J. Electronic Mater. - 1996. - 25. - P. 63-67.

School of Physics and DST/NRF Centre

Received 04.07.11

of Excellence in Strong Materials,

University of the Witwatersrand 